\title{
Rancang Bangun Aplikasi MusicMoo Dengan Metode MIR (Music Information Retrieval) Pada Modul Mood, Genre Recognition, dan Tempo Estimation
}

\author{
Johanes Andre R, Riyanarto Sarno, dan Dwi Sunaryo \\ Jurusan Informatika, Fakultas Teknologi Informasi, Institut Teknologi Sepuluh Nopember (ITS) \\ Jl. Arief Rahman Hakim, Surabaya 60111 Indonesia \\ e-mail: riyanarto,dwi@if.its.ac.id
}

\begin{abstract}
Abstrak-Saat ini,metode pemanggilan kembali informasi suatu musik atau yang sering disebut Music Information Retrieval (MIR) telah banyak diterapkan. Contohnya adalah pada suatu aplikasi Shazam ataupun Soundhound. Tetapi kedua aplikasi ini hanya menangani sebatas lagu apakah yang terkait ketika diperdengarkan. Untuk itu, tujuan penelitian ini adalah pengembangan lebih lanjut MIR yang lebih spesifik lagi, yaitu melakukan pemanggilan informasi lagu yang terkait kembali beserta detail lagu di antaranya adalah mood, genre, dan tempo lagu. Penelitian ini memakai ekstraksi fitur berbasis MPEG-7 yang oleh library Java bernama MPEG7AudioEnc. Hasil ekstraksi fiur ini berupa metadata yang terkandung fitur-fitur dalam bentuk angka digital yang merepresentasikan karakteristik suatu sinyal. Lalu melakukan pengambilan suatu fitur sesuai dengan masing-masing dengan metode Xquery yang diimplementasikan oleh library Java bernama BaseX. Fitur yang diambil akan diproses dengan melakukan Discrete Wavelet Transform (DWT) beserta level dekomposisi terbaik oleh library Python bernama Pywt. Setelah fitur-fitur dilakukan DWT, maka dilakukan penggabungan fitur pada suatu list beserta penyamaan panjang fitur untuk proses klasifikasi. Tahap terakhir adalah melakukan klasifikasi dengan menggunakan Support Vector Machine (SVM). Terdiri dari 2 tahap yaitu tahap training dan prediksi. Hasil akurasi keberhasilan pada penelitian ini untuk modul mood $75 \%$, genre $87,5 \%$ dan tempo $80 \%$.
\end{abstract}

Kata Kunci-Analisa Audio, MIR, MPEG-7, SVM.

\section{PENDAHULUAN}

$\mathrm{D}^{2}$ EWASA ini, industri media sudah berkembang sangat pesat, khususnya pada lagu. Lagu dapat ditemukan oleh masyarakat secara mudah. Mulai dari radio, Compact Disc (CD), internet, dan sumber-sumber lainnya.

Sebagai hasil dari ledakan terbaru dalam media tersebut, muncul juga suatu kebutuhan pokok untuk kalangan masyarakat agar bisa mengetahui informasi lagu yang lebih lengkap pada suatu lagu. Menjawab kebutuhan masyarakat tersebut, ditemukanlah metode Music Information Retrieval atau yang disingkat menjadi MIR. MIR adalah metode pemanggilan informasi suatu musik agar dapat memberikan informasi lagu yang kompleks.

Pada penelitian ini, eksperimen yang dilakukan terkait dengan analisa dan implementasi MIR pada modul mood, genre recognition, dan tempo estimation. Tujuan dari penelitian ini adalah memperkaya detail informasi suatu lagu.

Konsep yang digunakan pada penelitian ini adalah menggunakan ekstraksi fitur berbasis MPEG-7 yang sudah menjadi standar dalam konten multimedia berdasarkan ISO/IEC 15938 [1] [2]. Hasil ekstrasi fitur ini berupada metadata dalam format XML. Di dalam file metadata XML tersebut berisi terdapat fitur-fitur dalam bentuk angka-angka digital yang merepresentasikan karakteristik suatu sinyal sejumlah 17 fitur. Fitur- fitur yang didapatkan inilah memungkinkan untuk melakukan identifikasi kemiripan suatu lagu termasuk mood, genre, dan tempo berdasarkan kemiripan karakteristik sinyal yang dimiliki.

Diskusi pada jurnal ini dibagai dalam struktur sebagai berikut: Bab II membahas materi dan metode yang digunakan dalam percobaan ini. Bab III membahas hasil dan diskusi percobaan yang dilakukan. Terakhir pada Bab IV membahas kesimpulan dari hasil yang didapatkan dalam percobaan ini.

\section{II.MATERI DAN METODE}

Pada modul mood, audio fitur yang dipakai untuk proses adalah Audio Power dan Audio Harmonicity. Kedua fitur ini dipilih dan dikombinasikan karena untuk mood suatu lagu, dipengaruhi oleh suatu daya / naik turunnya amplitudo serta keselarasan harmonis nada [3]. Maka dipilihlah fitur Audio Power dan Harmonicity. Sedangkan Pada modul genre dan tempo, audio fitur yang dipakai untuk proses adalah Audio Spectrum Centroid, Audio Spectrum Spread, dan Audio Spectrum Flatness [4]. Fitur ini dipakai karena suatu lagu yang mempengaruhi genre dan tempo adalah informasi kejernihan suara (ASC), penyimpangan spektrum dari sinyal asli (ASS), dan kerataan properti suatu kekuatan spektrum (ASF). Maka untuk data train adalah gabungan ketiga sinyal yaitu ASC, ASS, dan ASF.

A. Audio Power [1]

Audio Power adalah fitur yang menggambarkan temporal daya sesaat dari sinyal audio. Koefisiennya dari kuadrat ratarata nilai gelombang sn dalam non-overlapping frame. Tujuannya adalah untuk membandingkan suatu label sinyal. Persamaan (1) adalah cara mendapatkan nilai AP. 


$$
A P(l)=\frac{1}{N_{\text {hop }}} \sum_{n=0}^{N_{\text {hop }}-1}\left|s\left(n+l N_{\text {hop }}\right)\right|^{2}(0 \leq l \leq L-1)
$$

di mana $\mathrm{L}$ adalah total jumlah frame waktu, $\mathrm{S}(\mathrm{n})$ merupakan rata-rata square waveform. Lw merupakan successive nonoverlapping, I adalah indeks frame dan $\mathrm{N}_{\text {hop }}$ adalah sampel antara successive non-overlapping.

\section{B. Audio Harmonicity [1]}

Audio Harmonicity adalah fitur yang mendeskripsikan 2 properti sinyal harmonik dari spektrum.Yang pertama harmonic ratio, yaitu rasio daya harmonik dari total daya dan yang kedua upper limit harmonicity yaitu frekuensi di atas yang spektrum tidak dapat dianggap harmonis. Tujuannya untuk membedakan suara harmonik (alat musik contohnya) dan suara non-harmonik (noise, pidato tidak jelas, dsb).

\section{Audio Spectrum Centroid [1]}

Audio Spectrum Centroid merepresentasikan sebagai karakteristik dari sebuah spektrum. Bisa juga menunjukkan pusat dari sebuah spekturm. Secara perseptual, ASC memiliki hubungan kuat antara kejernihan suara. Persamaan (2) adalah cara mendapatkan nilai ASC.

$$
A S C=\frac{\sum_{K^{\prime}=0}^{\left(N_{F / 2} / 2\right)} \log _{2}\left(\frac{f^{s}\left(k^{s}\right)}{1000}\right) P^{\prime}\left(k^{s}\right)}{\sum_{K^{\prime}=0}^{\left(N_{F T} / 2\right)} P^{\prime}\left(k^{\prime}\right)}
$$

di mana setiap frekuensi $\mathrm{f}^{\prime}\left(\mathrm{k}^{\prime}\right)$ dimodifikasi oleh spektrum daya sesuai koefisien $\mathrm{P}^{\prime}\left(\mathrm{k}^{\prime}\right)$.

\section{D.Audio Spectrum Spread Type [1]}

Audio Spectrum Spread didefinisikan sebagai momen sentral kedua spektrum $\log$-frekuensi. Fitur ini diekstraksi dengan mengambil root mean square (RMS) dari penyimpangan spektrum dari audio spectrum centroid. Persamaan (3) adalah cara mendapatkan nilai ASS.

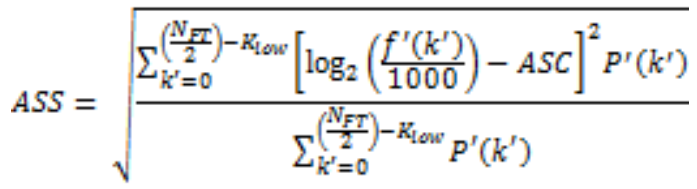

Di mana $\mathrm{P}$ ' $(\mathrm{k}$ ') adalah koefisien kekuatan spektrum yang dimodifikasi dan $\mathrm{f}^{\prime}(\mathrm{k})$ adalah frekuensi konsisten.

\section{E. Audio Spectrum Flatness Type [1]}

Audio Spectrum Flatness didefinisikan sebagai cerminan kerataan properti suatu kekuatan spektrum. Persamaan (4) adalah cara mendapatkan nilai ASF.

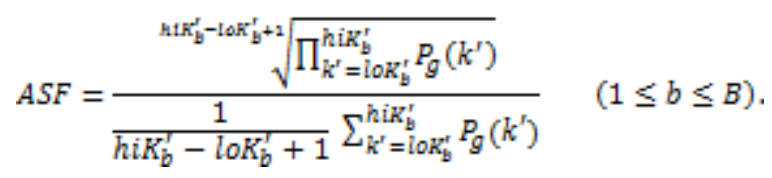

Di mana nilai : $\operatorname{Pg}\left(\mathrm{k}^{\prime}\right)=\mathrm{P}\left(\mathrm{k}^{\prime}\right), \mathrm{k}^{\prime}=\mathrm{loK}^{\prime} \mathrm{b}=\mathrm{loK} \mathrm{k}, \mathrm{k}^{\prime}=\mathrm{hiK}^{\prime} \mathrm{b}=$ hiKb

dan Bands $=1 \mathrm{kHz}$.

\section{F. Fast Fourier Transfrom}

Fast Fourier Transform (FFT) adalah metode untuk merubah sinyal dari time domain menjadi frequency domain [5]. Tujuannya adalah untuk mencari suatu informasi penting dalam frequency domain untuk tahap analisis [6][7].

\section{G. Discrete Wavelet Transform}

Discrete Wavelet Transform (DWT) adalah metode wavelet yang digunakan untuk melakukan dekomposisi pada wavelet sampai level $\mathrm{N}$ [5]. Tujuannya adalah untuk mengurangi noise pada sinyal dan memperkuat informasi di dalam sinyal tersebut dengan mempertahankan keutuhan informasi data [8] [9]. Ada banyak metode wavelet, namun dalam pengerjaan Tugas Akhir ini, metode wavelet yang digunakan adalah bior 2.8 dengan mengambil nilai approximation coefficients.

Untuk menentukan level dekomposisi ini, tidak boleh sembarangan karena ketika level dekomposisi tinggi, belum tentu yang baik. Sebaliknya malah merusak sinyal sehingga menghilangkan informasi yang terkandung sinyal asli. Maka perlu dilakukan pemilihan level dekomposisi wavelet yang terbaik [10].

Langkah pertama adalah melakukan perhitungan pada Persamaan (5) yang dilakukan pada Matlab.

$[$ max value, index $\max ]=\max (a b s(F F T(s-\operatorname{mean}(s)))))_{(5)}$

Maka akan didapatkan hasil max value dan max index. Kedua hasil ini digunakan untuk mencari Fh. Fh adalah Frequency Range pada Tabel 2.1. Untuk mendapatkan Fh, lakukan perhitungan pada Persamaan (6).

$F h=$ index $\max * F s / L$

Di mana Fs adalah Frekuensi sampling $=1024$, dan L adalah panjang sinyal. Hasil dari Fh dapat dilihat dari Tabel 2.1 sesuai dengan frequency range. Aturan untuk menentukan tingkat dekomposisi pada Tabel 1 dapat dinyatakan oleh Persamaan (7) [5]:

$\frac{f_{q}}{2^{N}+1} \leq f_{\text {char }} \leq \frac{f_{q}}{2^{N}}$

di mana $f_{q}$ adalah sampling frequency, $f_{c h a y}$ adalah dominant frequency, dan $N$ adalah level dekompsisi. Maka didapatlah level decompose wavelet terbaik.

Tabel 1.

Penentuan Decompose Level Wavelet

\begin{tabular}{ll}
\hline \hline $\begin{array}{l}\text { Decomposition } \\
\text { Level (L) }\end{array}$ & Frequency range $(\mathrm{Hz})$ \\
\hline 1 & $256-512$ \\
2 & $128-256$ \\
3 & $64-128$ \\
4 & $32-64$ \\
5 & $16-32$ \\
6 & $8-16$ \\
7 & $4-8$ \\
8 & $2-4$ \\
9 & $1-2$ \\
10 & $0.5-1$ \\
11 & $0.25-0.5$ \\
\hline \hline
\end{tabular}




\begin{tabular}{ll}
\hline \hline 12 & $0.125-0.25$ \\
13 & $0.0625-0.125$ \\
\hline \hline
\end{tabular}

\section{H.Xquery}

Xquery adalah bahasa untuk meng-query/ pemanggilan data di dalam suatu database dalam bentuk file XML [11]. Pada Tugas Akhir ini, Xquery digunakan untuk mengambil suatu fitur pada XML yang dihasilkan lewat ekstraksi fitur MPEG-7. Untuk mengimplementasikan Xquery, menggunakan library Java yang bernama BaseX [12].

\section{Dataset}

Dataset adalah kumpulan sutu data yang dilakukan untuk uji coba. Pada uji coba yang dilakukan untuk Tugas Akhir ini diambil dari 1000 Songs for Emotional Analysis of Music[13] [14]. Dari dataset ini sudah terdapat nilai valence / arousal sebagai penentuan mood, genre sebuah lagu, dan BPM lagu yang pasti dimiliki semua lagu.

\section{J. Mood}

Mood adalah keadaan emosional yang bersifat sementara, bisa beberapa menit bahkan beberapa minggu. Mood juga bisa diartikan tanggapan kita terhadap suatu rangsangan yang terjadi. Mood berbeda dengan emosi. Emosi adalah perasaan intens yang diarahkan pada seseorang atau sesuatu. Sedangkan mood adalah perasaaan yang tumbuh kurang intens yang dikarenakan kekurangan suatu stimulus. Secara umum, perbedaannya dipetakan menjadi berikut pada Tabel 1 [15] :

Tabel 1.

Perbedaan Antara Emosi dan Mood

\begin{tabular}{lc}
\hline \hline Emosi & Mood \\
\hline Durasi singkat & Durasi lama
\end{tabular}

Spesifik mengarah kepada suatu Biasanya lebih umum hal

Biasanya disertai dengan beragam Biasanya tidak disertai dengan ekspresi wajah ekspresi wajah

Pada musik, yang dipakai pada ujicoba kali ini adalah yang mood, dikarenakan musik adalah stilimulus yang bagus untuk meningkatkan mood seseorang.

\section{K. Genre}

Genre musik adalah pengelompokan musik sesuai dengan kemiripan satu sama lain. Sebuah genre dapat juga didefinisikan oleh teknik musik, gaya, dan konteks musik.

Terdapat banyak macam variasi genre pada suatu musik [16]. Dikarenakan sebuah genre pada suatu lagu terlalu banyak, maka pada percobaan ini dibatasi hanya sebatas genre umum suatu lagu yaitu classic, electronic, jazz, dan rock dimana di dataset juga sudah tersedia

\section{Tempo}

Tempo musik adalah ukuran kecepatan dalam birama lagu. Ukuran kecepatan bisa diukur dengan alat bernama metronome dan keyboard.
Secara umum, tempo dibagi menjadi 3 yaitu lambat, sedang, dan cepat. Tempo dibagi berdasarkan kecepatan nada [17]. Berikut pembagiannya berdasarkan BPM / Beats Per Minutes dipetakan pada Tabel 2:

Tabel 2.

Pembagian Estimasi Tempo

\begin{tabular}{cc}
\hline Satuan BPM & Estimasi Tempo \\
\hline$<100$ & Lambat \\
$100-135$ & Sedang \\
$>135$ & Cepat \\
\hline \hline
\end{tabular}

Untuk mendapatkan BPM suatu lagu, penelitian ini menggunakan software yang bernama MixMeister BPM Analyzer yang dapat diunduh secara gratis [18].

\section{Russel's Circumplex models}

Russel's Circumplex models adalah model yang digunakan untuk memetakan emosi dari dua kombinasi linear: arousal dan valence[19]. Pada uji coba kali ini, akan dipetakan berdasarkan skor arusal dan valence sesuai dengan Gambar 1 .

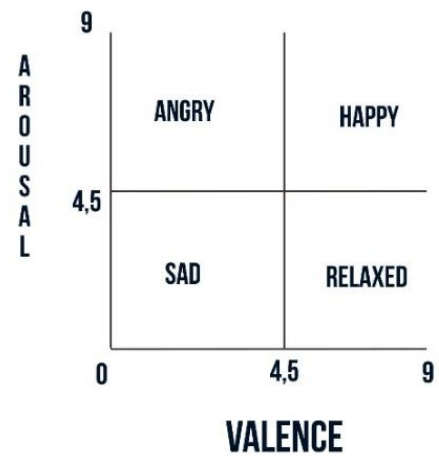

Gambar 1. Bagan Russel's Circumplex

\section{N. Suppor Vector Machine}

SVM adalah metode machine learning yang bekerja dengan mencari hyperlane terbaik (fungsi klasifier) yang memisahkan beberapa label yang berbeda [1]. Hyperlane yang optimal dapat ditemukan dengan cara mengukur margin / distance antara hyperlane dengan data yang paling dekat pada masing-masing labelnya.

SVM telah digunakan dalam berbagai eksperimen seperti klasifikasi identifikasi pembicara, pengenalan obyek, deteksi wajah dan klasifikasi vokal. SVM dapat mengklasifikasikan data multi-dimensi adalah yang pada dasarnya menentukan perbatasan antara dua kelas atau lebih.

Contoh pelatihan training data pada SVM menentukan parameter dari keputusan untuk mengklasifikasikan fungsi dari dua atau lebih kelas dan memaksimalkan margin selama fase pembelajaran. Setelah belajar, klasifikasi pola yang tidak diketahui dapat diperkirakan

Pada penelitian ini, dilakukan juga sesi training dan sesi testing untuk mencoba klasifikasi. Sesi training merupakan sesi melakukan pembelajaran terhadap variasi data-data yang dimiliki oleh suatu label sedangkan sesi testing merupakan proses uji coba prediksi pada suatu data yang baru. Metode SVM dipilih karena percobaan sebelumnya klasifkasi SVM menggunakan fitur MPEG-7 dan hasilnya baik [20]. Untuk melakukan implementasi SVM ini, digunakan library sklearn dari bahasa pemrograman Python menggunakan default kernel yaitu rbf. 


\section{HASIL DAN DISKUSI}

Aplikasi yang akan dibuat pada penelitian ini adalah program aplikasi mobile. Untuk alur jalannya sistem akan digambarkan pada Gambar 2.

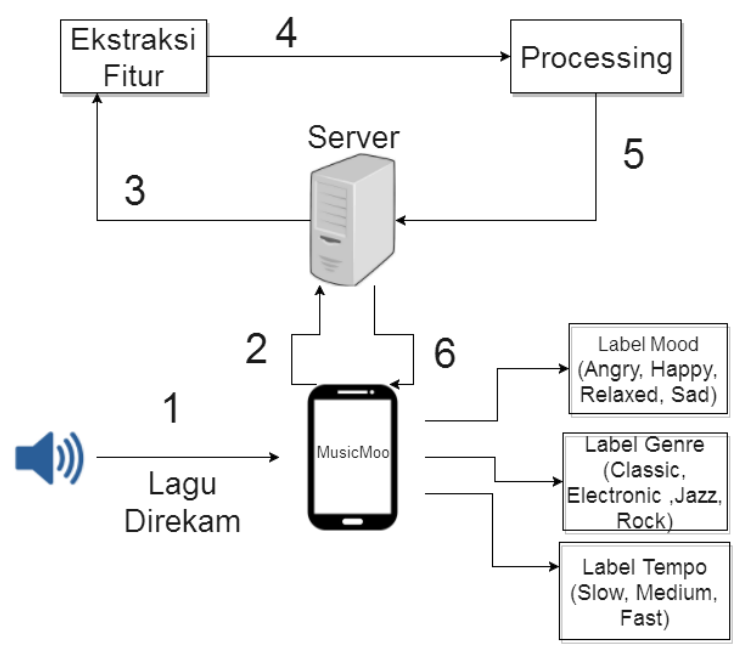

Gambar 2. Deskripsi Umum Sistem

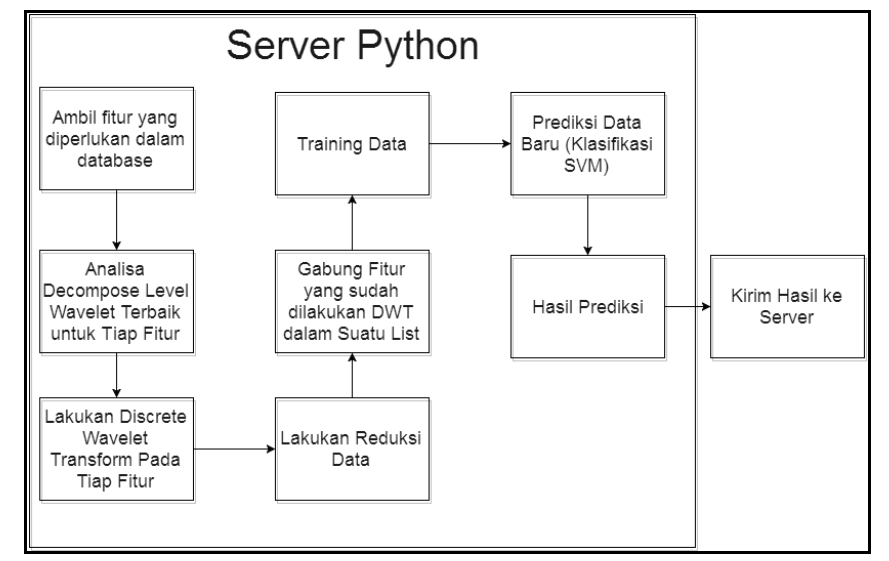

Gambar 3. Tahapan Ekstraksi Fitur Pada Server Java

Keterangan pada penomoran Gambar 3.1:

1. Sebuah lagu direkam melalui aplikasi mobile.

2. Lagu rekaman diupload ke server.

3. Lagu rekaman dilakukan ekstraksi fitur dan pengambilan fitur oleh server Java.

4. Fitur yang diambil dilakukan processing pada server Python (melakukan DWT dan klasifikasi).

5. Hasil akan dikirim kembali pada server.

6. Server akan menampilkan hasil pada aplikasi mobile.

\section{A. Ekstraksi Fitur}

Untuk detail tahapan proses yang terjadi di server Java akan digambarkan pada Gambar 3. Suatu lagu akan dilakukan ekstraksi fitur sehingga menghasilkan metadata XML berisi fitur-fitur MPEG-7. Setelah metadata dihasilkan, maka dilakukan pengambilan fitur oleh Xquery untuk mengambil fitur-fitur yang akan dipakai untuk disimpan dalam database. Jika sudah maka tugas pada server Java selesai dan dilanjutkan tahap processing yang ditangani oleh server Python.

\section{B. Processing}

Pada tahap ini, fitur yang dipilih akan masuk ke tahap processing. Fitur yang dipilih tadi akan dilakukan Discrete Wavelet Transform (DWT) dengan menggunakan tipe wavelet bior 2.8. Tujuannya adalah untuk menghilangkan noise yang terdapat pada sinyal. Implementasi yang dilakukan untuk melakukan DWT ini menggunakan library Python yang bernama Pywt. Untuk detail tahapan proses yang terjadi di server Python akan digambarkan pada Gambar 4.

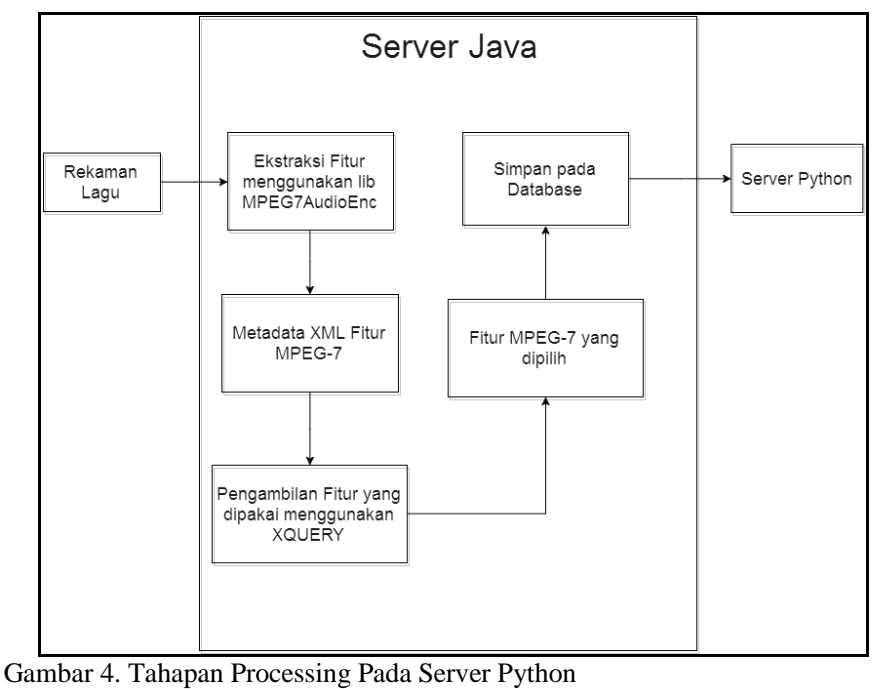

Kemudian dilanjutkan tahapan yaitu reduksi data. Reduksi data yang dimaksud adalah menyamakan panjang sinyal agar menjadi seragam untuk proses klasifikasi. Hal ini dilakukan karena ekstraksi fitur yang dihasilkan mempertimbangkan milidetik juga. Kami telah melakukan analisa pada 296 lagu dan mengambil panjang minimal pada setiap fitur yang telah dilakukan DWT. Berikut panjang sinyal minimal untuk tiap fitur akan dipaparkan pada Tabel 3.

Tabel 3 .

Panjang Minimal Tiap Fitur

\begin{tabular}{ll}
\hline \hline Fitur & Panjang minimal \\
Audio Power & 4.498 \\
Audio Harmonicity & 4.493 \\
Audio Spectrum Centroid & 51 \\
Audio Spectrum Spread & 51 \\
Audio Spectrum Flatness & 107.904 \\
\hline \hline
\end{tabular}

Maka panjang sinyal fitur setiap musik yang diambil sebanyak angka-angka tersebut, sisanya bisa diabaikan. Proses ini dijamin tidak akan merusak sinyal karena dari data awal panjang sinyal seragam semua yaitu 45 detik dan hanya membuang milidetik saja.

Setelah proses ini, akan masuk pada tahap berikutnya yaitu menggabungkan fitur dalam suatu list. Pada tahap ini, fiturfitur yang sudah dilakukan DWT akan digabungkan menjadi satu untuk menjadi suatu fitur baru.

Untuk modul mood, gabungan fitur yang terbentuk berasal dari Audio Power dan Audio Harmonicity. Sedangkan untuk modul genre dan tempo, gabungan fitur yang dibentuk adalah kombinasi dari Audio Spectrum Centroid, Audio Spectrum 
Spread, dan Audio Spectrum Flatness. Gabungan-gabungan fitur ini sudah dibagi sama panjang fitur per kolom untuk melakukan klasifikasi, sehingga keaslian informasi sinyal dijamin tidak akan rusak / berbeda.

Terakhir, adalah proses training data. Sebelum tahap klasifikasi menggunakan SVM, ada proses yang namanya melatih data. Tujuannya adalah agar mesin dapat mengetahui beragam karakteristik sinyal yang dimaksud sesuai dengan label tertentu. Implementasi SVM dilakukan menggunakan library Python yang bernama sklearn. Pada uji coba kali ini adalah melakukan training data untuk tiap modul (mood, genre, dan tempo) sebanyak 65 data per label. Berikut akan diperinci pada Tabel 4.

Tabel 4.

Perincian Data Training

\begin{tabular}{ccc}
\multicolumn{2}{c}{ Modul } \\
\hline \hline & Label & Jumlah Data Training \\
\cline { 2 - 3 } & Angry & 65 \\
& Happy & 65 \\
& Relaxed & 65 \\
Mood & Sad & 65 \\
\hline & Classic & 65 \\
& Electronic & 65 \\
& Jazz & 65 \\
Genre & Rock & 65 \\
\hline & Slow & 65 \\
& Medium & 65 \\
\hline \hline
\end{tabular}

Setelah mesin membelajari karakteristik-karakteristik sinyal sesuai yang diberikan, maka prediksi data baru pun dapat dilakukan. Sehingga karakteristik lagu rekaman tadi dapat diprediksi memiliki mood, genre, ataupun tempo apa sesuai dengan karakteristik sinyal yang diberikan. Hasil prediksi akan dibawa kembali ke server untuk ditampilkan pada aplikasi mobile.

\section{Hasil Percobaan}

Pada percobaan kali ini, testing yang digunakan adalah 35 sampel untuk mood, 30 sampel tempo, dan 24 sampel genre.

Akurasi dihitung menggunakan Persamaan (21) yang merupakan perhitungan dengan cara Cohen's kappa sebagai berikut:

$A C C=\frac{T R U E}{\text { TOTAL DATA }} * 100 \%$

Secara berurutan, Tabel 5, Tabel 6, dan Tabel 7 adalah hasil uji coba pada modul mood, tempo, dan genre. Dengan menggunakan Persamaan (8), maka akurasi yang didapatkan untuk modul $\operatorname{mood} 75 \%$, tempo $80 \%$, dan genre $87,5 \%$.
Tabel 5 .

Hasil Percobaan Modul Mood

\begin{tabular}{lllll}
\hline \hline & & \multicolumn{3}{c}{ Testing } \\
Actual & Angry & Happy & Relaxed & Sad \\
\hline Angry & 4 & 1 & 0 & 0 \\
Happy & 0 & 10 & 0 & 0 \\
Relaxed & 0 & 3 & 2 & 5 \\
Sad & 0 & 0 & 0 & 10 \\
\hline \hline
\end{tabular}

Tabel 6.

Hasil Percobaan Modul Tempo

\begin{tabular}{llll}
\hline \hline & \multicolumn{3}{c}{ Testing } \\
Actual & Fast & Medium & Slow \\
\hline Fast & 5 & 5 & 0 \\
Medium & 0 & 10 & 0 \\
Slow & 0 & 1 & 9 \\
\hline \hline
\end{tabular}

Tabel 7.

Hasil Percobaan Genre

\begin{tabular}{lrrrr}
\hline \hline & \multicolumn{4}{c}{ Testing } \\
Actual & Classic & Electronic & Jazz & Rock \\
\hline Classic & 6 & 0 & 0 & 0 \\
Electronic & 0 & 6 & 0 & 0 \\
Jazz & 1 & 1 & 4 & 0 \\
Rock & 0 & 1 & 0 & 5 \\
\hline \hline
\end{tabular}

\section{KESIMPULAN}

Pada modul mood, audio fitur yang mempengaruhi adalah Audio Power dan Audio Harmonicity. Pada modul genre, audio fitur yang berpengaruh adalah fitur Audio Spectrum Centroid, Audio Spectrum Spread, dan Audio Spectrum Flatness. Terakhir, pada modul tempo, audio fitur yang berpengaruh adalah fitur Audio Spectrum Centroid, Audio Spectrum Spread, dan Audio Spectrum Flatness.Fitur yang berpengaruh pada tempo sama seperti dengan genre. Tingkat akurasi untuk masing-masing modul sudah baik di mana mood $75 \%$, genre $87,5 \%$, dan tempo $80 \%$.

\section{DAFTAR PUSTAKA}

[1] H.-G. Kim, N. Moreau, and T. Sikora, MPEG-7 Audio and Beyond: Audio Content Indexing and Retrieval. John Wiley \& Sons, 2005.

[2] ISO/IEC (2001), "Information Technology — Multimedia Content Description Interface — Part 4: Audio," FDIS 15938-4:2001(E), June.

[3] Z. W. Ras and A. Wieczorkowska, Advances in Music Information Retrieval, 1st ed. Springer Publishing Company, Incorporated, 2010.

[4] S. Li, H. Li, and L. Ma, "Music Genre Classification Based on MPEG-7 Audio Features," in Proceedings of the Second International Conference on Internet Multimedia Computing and Service, New York, NY, USA, 2010, pp. 185-188.

[5] R. X. Gao and R. Yan, Wavelets: Theory and Applications for Manufacturing, 2011 edition. New York; London: Springer, 2010.

[6] B. T. Nugraha, R. Sarno, D. A. Asfani, T. Igasaki, and M. N. Munawar, "Classification of driver fatigue state based on EEG using Emotiv EPOC+," J. Theor. Appl. Inf. Technol., vol. 86, no. 3, pp. 347-359, Apr. 2016.

[7] R. Sarno, M. N. Munawar, B. T. Nugraha, R. Sarno, M. N. Munawar, and B. T. Nugraha, "Real-Time Electroencephalography-Based Emotion Recognition System," Int. Rev. Comput. Softw. IRECOS, vol. 11, no. 5, pp. 456-465, May 2016. 
[8] R. Sarno, B. T. Nugraha, M. N. Munawar, R. Sarno, B. T. Nugraha, and M. N. Munawar, "Real Time Fatigue-Driver Detection from Electroencephalography Using Emotiv EPOC+," Int. Rev. Comput. Softw. IRECOS, vol. 11, no. 3, pp. 214-223, Mar. 2016.

[9] M. N. Munawar, R. Sarno, D. A. Asfani, T. Igasaki, and B. T. Nugraha, "Significant preprocessing method in EEG-Based emotions classification,” J. Theor. Appl. Inf. Technol., vol. 87, no. 2, pp. 176190, May 2016.

[10] D. R. Wijaya, R. Sarno, and E. Zulaika, "Information Quality Ratio as a novel metric for mother wavelet selection," Chemom. Intell. Lab. Syst., vol. 160, pp. 59-71, Jan. 2017.

[11] M. Gruhne, R. Tous, J. Delgado, M. Doeller, and H. Kosch, "Introduction of an Mpeg-7 Query Format."

[12] B. Team, "The XML Database," 27-May-2015. [Online]. Available: http://basex.org/home/. [Accessed: 15-Jan-2017].

[13] M. Soleymani, M. N. Caro, E. M. Schmidt, C. Ya Sha, and Y.-H. Yang, "Emotion in Music Database - MediaEval 2013 - aka 1000 songs." [Online]. Available: http://cvml.unige.ch/databases/emoMusic/. [Accessed: 19-Dec-2016].

[14] M. Soleymani, M. N. Caro, E. M. Schmidt, C.-Y. Sha, and Y.-H. Yang, "1000 Songs for Emotional Analysis of Music," Proc. ACM Int. Multimed. Conf. Exhib., vol. 6, no. 1, pp. 1-14, 2015.

[15] D. Hume, Emotion and Moods. Organizational behavior, 2012.

[16] "About the Music Genres List Site," Music Genres List. [Online]. Available: http://www.musicgenreslist.com/about-music-genre-site/. [Accessed: 15-Jan-2017].

[17] Y.-Y. Chang and Y.-C. Lin, "Music Tempo (Speed) Classification," 2005.

[18] "MixMeister BPM Analyzer," Softonic. [Online]. Available: https://mixmeister-bpm-analyzer.en.softonic.com/. [Accessed: 15-Jan2017].

[19] M. Nardelli, G. Valenza, A. Greco, A. Lanata, and E. P. Scilingo, "Recognizing Emotions Induced by Affective Sounds through Heart Rate Variability," IEEE Trans. Affect. Comput., vol. 6, no. 4, pp. 385394 , Oct. 2015.

[20] C.-H. Lin et al., "SVM-Based Sound Classification Based on MPEG-7 Audio LLDs and Related Enhanced Features," in Convergence and Hybrid Information Technology, 2012, pp. 536-543. 